\title{
Causation comes in degrees
}

\author{
Huzeyfe Demirtas ${ }^{1}$ (I)
}

Received: 28 March 2021 / Accepted: 15 November 2021 / Published online: 1 March 2022

(C) The Author(s), under exclusive licence to Springer Nature B.V. 2022

\begin{abstract}
Which country, politician, or policy is more of a cause of the Covid-19 pandemic death toll? Which of the two factories causally contributed more to the pollution of the nearby river? A wide-ranging portion of our everyday thought and talk, and attitudes rely on a graded notion of causation. However, it is sometimes highlighted that on most contemporary accounts, causation is on-off. Some philosophers further question the legitimacy of talk of degrees of causation and suggest that we avoid it. Some hold that the notion of degrees of causation is an illusion. In this paper, I'll argue that causation does come in degrees.
\end{abstract}

Keywords Degrees of causation - More of a cause - Causal contribution - Causal responsibility $\cdot$ Moral responsibility

Which is the main cause of obesity-genetics, or unhealthy diet? Was it due more to Suzy's absence or the lack of good food that last night's party was a bore? Which of the two factories contributed more to the pollution of the nearby river? Is alcohol more important cause of heart attack than smoking? We typically don't question the legitimacy of ordinary questions like these. Yet these questions might suggest something controversial - that causation admits of degrees.

It's sometimes highlighted that on most contemporary accounts causation is on-off (Sartorio 2010, 2015). Some authors question whether the talk of degrees of causation is legitimate (Pearson 1980, Barker and Steele 2015). Some hold that the talk of degrees of causation is misleading (Zimmerman 1985). It's also argued that the notion of degrees of causation is an illusion and needs to be explained away (Sartorio 2020). As opposed to this, some authors hold the thesis that causation comes

Huzeyfe Demirtas

hdemirta@syr.edu

1 Department of Philosophy, Syracuse University, Syracuse, New York, USA 
in degrees. ${ }^{1}$ However, the literature on this thesis has two big gaps. One, it's often unclear what's meant by degrees of causation. And two, most importantly, the main objections against this thesis remain unanswered. Hence, it would seem, this thesis hasn't properly been defended in the literature. This paper aims to fill these gaps and argues that causation comes in degrees. ${ }^{2}$

In §1, I'll distinguish four different senses of degrees of causation and clarify the thesis that I'll argue for. In \$2 through \$5, I'll list the four main objections from the literature to the thesis that causation comes in degrees and argue that they fail. In §6, I'll argue that it's theoretically too costly to deny this thesis. I'll conclude-since we have no good reason to reject this thesis and it's too costly to deny it- that this thesis is true.

\section{Four senses of degrees of causation}

In this section, I'll distinguish four different senses of degrees of causation in the literature. First, suppose Suzy and Billy are both very funny. Their attendance to tonight's office party made it an exceptionally fun party. We might wonder about Suzy's causal significance on the party's being fun compared to Billy's causal significance. That is, for the causal factors $c_{1}, c_{2}, c_{3}, \ldots c_{n}$, in the previous causal link that brought $e$ about, we might wonder about the relative causal influences of $c_{1}, c_{2}$, $c_{3}, \ldots c_{n}$ on $e$. For instance, the degree of Billy's causal significance might be twice the degree of Suzy's causal significance. After Northcott (2005b), I'll call this the relative sense of degrees of causation. Degrees of causation in this sense is endorsed by most, if not actually all, those who hold that causation comes in degrees. ${ }^{3}$ And I'll argue that causation comes in degrees in this sense.

Notice that the relative sense of degrees of causation could be applied not only within a case but also across distinct cases. Imagine that there was another and equally fun office party in the next building tonight. Imagine also that Timmy and Lily were the funny people in this second party. We might wonder about, say, Billy's causal significance to the first party's being fun relative to Lily's causal significance

\footnotetext{
${ }^{1}$ Cf., e.g., Northcott (2005b), Braham and van Heeves (2009), Moore (2013), Mumford (2013), Bernstein (2017), and Sprenger (2018).

${ }^{2}$ To be clear, I'll defend the thesis that there are degrees of causation, and not any specific account of (measuring) degrees of causation. Also, one might object that Moore (2009) defends this thesis. Indeed, in chapter 3 (p. 71) of his book he says that he'll defend this thesis in chapters 5-6. However, in chapters 5-6 he says no more in favor of this thesis than, roughly, that it is assumed in legal practice. As Bebe puts in her review of Moore's book, "Moore offers very little by way of motivation or argument" for this thesis (Bebe 2013, p. 105).

${ }^{3}$ Kaiserman (2016) distinguishes between scalarity of causal relations and degrees of causal contribution, and rejects the former and endorses the latter. His notion of scalarity of causal relations will, in my taxonomy, fall under the fourth sense of degrees of causation below. His notion of degrees of causal contribution is basically what I call the relative sense of degrees of causation. "Degrees of causation," "degrees of causal contribution," and their variations are often used interchangeably in the literature both by those who think that causation comes in degrees and those who don't (cf. e.g., Moore (2009, p. 71), Braham and van Heeves (2009, p. 324), Sartorio (2010, p. 836), Alexander and Ferzan (2012, p. 83), Mumford (2013, p. 109)).
} 
to the second party's being fun. It might be that the degree of Lily's contribution to the second party's being fun is twice the degree of Billy's contribution to the first party's being fun. This might well be the case if Lily is two times funnier than Billy. ${ }^{4}$

Notice also that the examples above are instances of token-level causal relations. We can also consider type-level causal relations-e.g., alcohol causes heart attack. One might, for instance, hold that alcohol is a more significant cause of heart attack than smoking because, say, in more individual instances of heart attacks alcohol is the more significant cause than smoking or because alcohol causes heart attacks more often than smoking. Objections in the literature against degrees of causation typically focus only on token-level causal relations. ${ }^{5}$ Since, as I'll argue, these objections fail, they fail for both types of causal-relations. Moreover, as the discussion below will further demonstrate, it's just as costly to deny degrees of causation in type-level relations. Hence, I'll be arguing for degrees of causation in both sorts of causal relations.

Second, suppose Suzy, Billy and all their colleagues received the good news earlier that day that they all got a raise. So, they all were already in a good mood, which was among the reasons why tonight's party was fun. We might now wonder about Billy's causal impact on the party's being fun compared to the causal impact of the good news. That is, given an outcome $e$, we might wonder about the causal strength of a cause of $e$ in the previous link compared to a cause of $e$ in a link further back in the causal chain. This sense of degrees of causation is essentially no different than the relative sense of degrees of causation. But I must qualify this. It's typically accepted that causation is transitive: roughly, if $d$ causes $c$, which in turn causes $e$, then $d$ causes $e$. Yet some think that causation is intransitive. If causation is intransitive, in some cases there may be no degrees of causation in this second sense. This is because if $d$ is not a cause of $e$, there's no question of the extent to which $d$ causes $e$. However, that causation is intransitive doesn't entail that it's never the case that if $d$ causes $c$, and $c$ causes $e$, then $d$ causes $e$. Transitivity might still sometimes obtain. ${ }^{6}$ Hence, even if causation is intransitive, there may still be degrees of causation in this second sense-only in a more limited scope.

The debate in the literature over this sense of degrees of causation-rather than being directly on whether causation comes in degrees in this sense-is typically conducted via a specific criterion for measuring degrees of causation. ${ }^{7}$ The criterion in question, roughly, is that causal strength gets diluted as it's transmitted from one causal link to another. For instance, a causal factor, $d$, that's further back in the causal chain might have smaller causal influence on an outcome, $e$, compared to another cause, $c_{1}$ or $c_{2}$, of $e$ that's in the link right before $e$. Indeed, that might depend on the initial causal strength of $d$ and how many causal links it's transmitted through before

\footnotetext{
${ }^{4}$ Among those who hold that causation comes in degrees, Moore (2012, p. 448) might be pessimistic about relative sense of degrees of causation across distinct cases. However, it's not clear enough whether what he has in mind is this one or the third sense of degrees of causation I'll mention below.

${ }^{5}$ I suspect this is because it seems easier to argue for degrees of causation in type-level relations-especially once degrees of causation in token-level relations is established.

${ }^{6}$ Cf. Hall (2000), and Paul and Hall (2013, ch.5) for further discussion on transitivity of causation. Cf. Mumford (2013) who argues that his account of causation entails that causation is not always transitive.

${ }^{7}$ Cf. e.g., Moore (2009, pp. 121-3), Alexander and Ferzan (2012, p. 84), Mumford (2013, p. 111), Bebe (2013, pp. 105-6), Tadros (2018, pp. 428-9).
} 
$e$. If $d$ had a massive causal influence to begin with, even its diluted causal influence might turn out to be bigger than the causal influence of $c_{1}$ or $c_{2}$ (Moore 2013, p. 127). Now notice that the criterion in question is about how to measure the relative strength of causal factor, $d$, that's further back in the causal chain. But even if this criterion is false, it doesn't follow that the causal influence of $d$ cannot be compared to the causal influence of $c_{1}$ or $c_{2}$. If $d$ is a cause of $e$, I see no reason why we can compare the causal influence of $c_{1}$ to that of $c_{2}$, but can't compare the causal significance of $d$ to that of $c_{1}$ or $c_{2}$. That is, if causation comes in degrees in the first sense above, it also comes in degrees in this second sense. As Moore - the biggest defender of the criterion above - also puts, of the two senses of degrees of causation above, the first one is the most basic (Moore 2013, p. 123). Hence, I'll focus on degrees of causation in the first sense above.

Third, in addition to Suzy's impact on the party's being fun compared to, say, Billy's impact, we might also wonder about Suzy's impact in its own right. For instance, given that everyone in the office is already in a good mood, we might wonder what the impact of Suzy's presence or absence would be on the party's being fun. After Northcott (2005b), I'll call this the absolute sense of degrees of causation. That causation comes in degrees in this sense intuitively seems plausible. However, among those who believe that causation comes in degrees, it's unclear whether most of them endorse degrees of causation in this sense. ${ }^{8}$ The kinds of examples they use to illustrate their views don't strongly suggest an endorsement or rejection of this sense of degrees of causation. Moreover, among those who reject that causation comes in degrees, I'm not aware of anyone who objects particularly to this sense of degrees of causation. But much of what I say below works also in favor of degrees of causation in this sense.

Fourth, it's commonly held that causation is a relation between cause and effect. One might then wonder whether the idea that causation comes in degrees might mean that an effect can be more caused or less caused. I'll call this - the idea that an effect can be more/less caused - the scalarity of effect sense of degrees of causation. Considering again that tonight's party was fun, the question is whether it could have been more caused or less caused. Or supposing that it's raining outside now, the question is whether it could be said to be more caused or less caused. Among those who believe that causation comes in degrees, some explicitly reject it in the scalarity of effect sense. ${ }^{9}$ For most others, their own illustrations of what they have in mind and their context strongly suggest that scalarity of effect sense is not in their purview. Among

\footnotetext{
${ }^{8}$ However, cf. Northcott (2005b) for a defense of this sense of degrees of causation. Cf. Fitelson and Hitchcock (2011) for a survey of various measures of degrees of causation some among which can plausibly be considered as aiming to measure degrees of causation in this sense. Also, one way to see the difference between the relative sense and the absolute sense of degrees of causation is to think of the former as an ordinal measure and the latter as a cardinal measure. However, the word "absolute" can still be a bit misleading. One might, for instance, think that it implies that a given causal factor has a fixed quantity of causal influence that applies in all contexts and for all outcomes. This seems wrong. Cf. Northcott (2008, pp. 88-9) for a related discussion.

${ }^{9}$ Moore calls the idea that some event can be more or less caused "bizarre" (2012, p. 447). Kaiserman argues that causation is "not a scalar relation" (2016, p. 389). It seems to me from his discussion that it is, what I call, the scalarity of effect sense of degrees of causation that he rejects. Moore sometimes expresses his view of degrees of causation as "causation is a scalar relation" $(2009$, p. 105). But when he
} 
those who reject degrees of causation, I'm not aware of anyone raising an objection explicitly to this sense of degrees of causation. Hence, I'll leave this sense of degrees of causation aside.

\section{Objection 1: on most contemporary accounts causation is on-off}

As a worry about the thesis that causation comes in degrees, it is sometimes noted that on most contemporary accounts causation is all or nothing, that it doesn't admit of degrees. ${ }^{10}$

However, what exactly should be worrisome is unclear. This is because it's unclear how the accounts in question should suggest that causation doesn't admit of degrees. The worry might arise because most accounts of causation "focus on the binary question of whether something is a cause" (Lagnado et al., 2014). One might then be tempted to think that something either is or isn't a cause of an outcome- there are no other options. Hence, causation doesn't come in degrees. ${ }^{11}$ But this doesn't follow. That something either is or isn't a cause is just a consequence of the law of excluded middle. ${ }^{12}$ It doesn't say anything about whether something could be more or less of a cause. Similarly, it's true that a belief either is or isn't justified. But it doesn't follow that epistemic justification doesn't come in degrees. It does-as it's commonly accepted, a belief can be more or less justified (Feldman 2003, p. 21, Pappas 2017).

To further see that it's unclear what should be worrisome, let's take a closer look at some contemporary accounts of causation. For instance, productive theories of causation hold that causation is a matter of producing another event. ${ }^{13}$ According to one prominent example of such an account, $c$ causes $e$ if there's a transfer of conserved quantity (e.g., force, or energy) from $c$ to $e$ (Dowe 2000). Suppose you hit a glass and it falls off the table. You brought about this outcome in virtue of transferring energy to the glass. Given this picture of causation, one might think that a factor either does transfer energy to an outcome or it doesn't. True enough, but one might still wonder as to how much energy a factor transfers to an outcome. For instance, suppose three people carry a heavy marble top, rectangular dining table from the truck all the way into the kitchen. Two of them, who are regular people, each hold two separate corners on one side, and one of them, who is unusually large and strong, holds both corners on the opposite side. It seems natural to think that the strong one causally contributed

further explains his view, it's clear that he has in mind the first two senses of degrees of causation above (2012, pp. 446-7).

${ }^{10}$ Cf. Sartorio $(2010,2015)$. Mumford (2013), who argues that his account of causation leaves room for degrees of causation, also notes this worry for many other theories of causation.

11 Compare: "Causation [...] exists or it does not, and if it does exist one does not speak of "degrees" of causation" (Pearson 1980, p. 346). Here, Pearson is denying "comparative [causal] contribution." It's clear from his context that what he has in mind is, what I called, the relative sense of degrees of causation.

12 Thanks to Ben Bradley for the helpful suggestion here.

13 The question of causal relata is controversial. Events, facts, agents, states of affairs, and features are among the possible candidates. The standard view holds that they're events (Paul and Hall 2013, Schaffer 2016). I don't take a position on this. However, for ease of exposition, I'll treat causation as a relation between events. 
more to the outcome than the other two people. One plausible way to account for this thought is to think that the strong person is more of a cause of the outcome because she transferred more energy to the outcome. One might then hold that the degree of causation is about how much energy a given factor transfers to an outcome. ${ }^{14}$ Hence, it seems plausible to hold that productive theories of causation can account for degrees of causation.

Let's now turn to counterfactual theories of causation according to which causation is a matter of counterfactual dependence between wholly distinct events (Hall 2004). On the simplistic counterfactual view $c$ is a cause of $e$ just in case $e$ counterfactually depends on $c$. That is, $c$ causes $e$ just in case had $c$ not occurred, $e$ would not have occurred. The dependence relation in question doesn't initially seem to leave room for gradation: either the counterfactual dependence holds, or it doesn't. Hence, one might be inclined to hold that counterfactual theories of causation cannot account for degrees of causation. But this is mistaken. Consider the following scenario. Billy and Suzy work in an apple orchard. Today, they're asked to pick up 1000 apples that are ripe, firm and with no indents or discoloration. At the end of the day, Billy counts 400 apples in his basket, and Suzy 600. They bring the apples to the office and call it a day. It is natural to think that Suzy causally contributed more to, or she's more of a cause of, the outcome than Billy. Moreover, it seems plausible to think that Suzy contributed more even if Suzy and Billy spent equal amount of effort. They both worked nonstop, they are equally tired in the end, they spent equal amount of energy and so on. After all, Suzy might just have worked smart rather than hard, and hence got more work done. Now both Billy and Suzy together stand in a counterfactual dependence relation with the outcome-i.e., if not for both their conducts, the outcome wouldn't have occurred. But it is also true that the portion of the outcome that depends on Suzy's conduct is bigger than the portion of the outcome that depends on Billy's conduct. One might then hold that the degree of causation is about the portion of an outcome that counterfactually depends on a given factor. ${ }^{15}$ Hence, it seems plausible to hold that counterfactual theories of causation can account for degrees of causation.

Lastly, let's consider probabilistic theories of causation according to which causation is a matter of raising the probability of the occurrence of an event (Eells 1991). One might again think that a factor either does or it doesn't raise the probability of

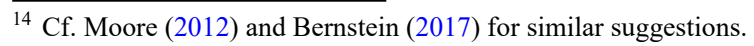

${ }^{15}$ This account is inspired by a suggestion made to me by Hille Paakkunainen. A similar suggestion can also be found in Tadros (2018). Notice that the outcome in question is easily decomposable into partsi.e., 400 plus 600 apples. However, consider multiple people killing someone. It might be difficult to see how the talk of portions of the outcome, i.e., death, will apply in such a case. I'll assume that the general idea here could be adjusted after more sophisticated accounts of the portion of an outcome. There are also more fully developed counterfactual measures of degrees of causation that don't run into this problem. Cf. Chockler and Halpern (2004), and Lewis (2004). Chockler and Halpern's measure receives empirical support from people's actual causal judgements (Gerstenberg et al., 2018, Lagenhoff et al., forthcoming). Also consider pluralists (who hold that there are multiple fundamental concepts of causation) (Hall 2004) and - what might be called - unifiers (who hold that the competing conceptions of causation can consistently be brought together under a single account) (Gerstenberg et al., forthcoming). It's open to both camps to hold that the binary question of whether $c$ is a cause of $e$ is to be evaluated by one conception of causation (e.g., the counterfactual conception) and the extent of $c$ 's causal influence on $e$ is to be evaluated by another (e.g., the productive conception, or the probabilistic conception). Such a tiered account can also avoid running into this problem. (Thanks to Matthias Rolffs for the suggestion.)
} 
an outcome. But one might also wonder about how much a given factor increases the probability of an outcome. Consider the following scenario. Suzy had her six-monthly eye exam appointment yesterday, but missed it. She barely feels a problem with her glasses now, but they seem to work fine overall. And since her prescription didn't change in the last two years, she's not too worried about missing the appointment. She needs to drive thirty minutes to work but there's also a heavy rainstorm outside. She's a good driver, and she has driven in rainstorms before. Unfortunately, however, this time around she gets into an accident on her way to work. It seems that the heavy rainstorm is more of a cause of the accident than Suzy's eyesight. One might think that this is because mildly improper eyesight tends to bring about accidents only to a minimal degree, whereas heavy rainstorms have much bigger potential to bring about accidents. Or, while a mildly improper eyesight seldom brings about accidents, it's all too frequent that a heavy rainstorm brings about accidents. That is, a heavy rainstorm increases the probability of an accident much more than a mildly improper eyesight. One could then hold that a factor's degree of causal contribution is about how much that factor increases the probability of an outcome. ${ }^{16}$ Hence, it seems plausible to hold that probabilistic theories of causation can account for degrees of causation.

To be sure, I don't mean that the accounts of causation above entail or even strongly suggest that there are degrees of causation. But these accounts don't inherently exclude a graded notion of causation either. Hence, I conclude that the first objection fails to raise a significant worry for the thesis that causation comes in degrees.

\section{Objection 2: no room for thinking of more or less of a cause}

We now turn to the second objection. Suppose ten teenagers of varying strengths come together to push a boulder down the hill. None of them is strong enough to push the boulder on their own, and each of them is needed to get the job done. But if the inputs of each of these teenagers are necessary and none is sufficient for the outcome, then it is misleading to think of any of them as more/less strong or important cause of the outcome. After all, if any of them weren't there, the boulder couldn't have been pushed down. None of them on their own could push the boulder down either. Hence, the objector contends, if each factor is causally necessary and none is causally suf-

\footnotetext{
${ }^{16} \mathrm{Cf}$. Kaiserman (2016) for further details on an account along these lines. I mean to suggest neither that this is the only way probabilistic theories of causation can account for degrees of causation, nor that the above is the only conception of probability or probabilistic theory of causation. See Fitelson and Hitchcock (2011) for a survey of several other proposals for analyzing degrees of causation in terms of probabilities. See Sprenger (2018) for a discussion on how to adjudicate between these competing proposals and his argument favoring one of them over the others. Moreover, the three kinds of theories of causation discussed above are not the only kinds of theories of causation. For instance, there are also primitivist theories of causation - i.e., those that suggest that causation is unanalyzable. Although it depends also on how much such a theory can tell us about causation despite its primitivism, it's possible that a primitivist theory can also account for degrees of causation. See Moore (2012, pp. 447-8, 2013, p. 126), and Mumford (2013) for discussions on this.
} 
ficient for the outcome, then there's no room for thinking about any of them as more/ less of a cause of the outcome. ${ }^{17}$

An initial worry about this objection might be that it's based on a specific kind of case - one in which multiple people jointly cause an outcome. But the point in the objection could be further generalized since anytime we cause an outcome, there are multiple causal factors at play. For instance, lighting a match takes many other causal factors in addition to dragging the match across the striker-appropriate temperature, oxygen in the air, and so on. Here again, each of these factors is causally necessaryin the above sense-and none is causally sufficient for the outcome. However, one might still worry that the point isn't general enough - that not in all cases where there are multiple causal factors each factor is causally necessary and none is causally sufficient for the outcome. Take, for instance, overdetermination cases. By definition, they're the kind of cases where there are multiple sufficient causes for an outcome. Yet, I'll ignore this complication, and take that the objection raises a general enough concern.

The objection again is that, concerning a set of causal factors, if all of them are causally necessary and none is sufficient for an outcome, there's no room for thinking about any of them as more/less of a cause of the outcome. Yet, it's unclear why this should be the case. Suppose we need ten gallons of water in a tank. It so happens that Suzy has seven gallons of water, and Timmy has three, and no one else has any water. Suzy and Timmy pour the water they have into the tank, and we have the ten gallons of water. Both Suzy's action and Timmy's action are causally necessary - in the above sense - and none is causally sufficient for the outcome. But it seems appropriate to think that Suzy is more of a cause of the outcome, or she causally contributed more to the outcome, than Timmy. One might further think that this is because Suzy increases the probability of the outcome more, or because she transfers more energy to the outcome. The point is that, regarding a set of causal factors, even if all of them are causally necessary and none is sufficient for an outcome, they could still differ in respects that are plausible ways of thinking about degrees of causation. Hence, I conclude that the second objection fails to show that causation doesn't come in degrees.

\section{Objection 3: the notion of degrees of causation is an illusion}

Let's now turn to the third objection. Sartorio (2020) argues that the thesis that causation comes in degrees is false. Her argument relies on two criteria for measuring degrees of causation that she suggests. I'll now present these criteria first and then her argument. Consider the following pair of cases:

Bullet: You are the only shooter aiming at a victim. You shoot and the victim dies.

\footnotetext{
17 Thanks to Robert Van Gulick for raising this objection. Zimmerman (1985) raises a similar concern and argues that we should avoid the talk of causing an outcome in varying extents. See Northcott (2005a) for a similar concern and his reply to it.
} 
Bullet-with-Bird: When you shoot, a bird collides with the bullet and slows the bullet down a bit, reducing its momentum in such a way that it alone is no longer enough to kill the victim. But the bird's flying by also independently dislodges a loose boulder that is not large enough to crush the victim to death on its own. Although neither the bullet nor the boulder is enough in itself to cause the death, together they are sufficient to cause it.

On the assumption that there are degrees of causation, it seems natural to think that you make a less substantial contribution to victim's death in Bullet-with-Bird than you do in Bullet. We can account for this thought via the following criterion:

(Sufficiency Criterion) How much a cause contributes to an effect is a matter of how close it comes to providing a sufficient condition for an effect.

In Bullet, your bullet on its own is sufficient to kill the victim. Whereas in Bulletwith-Bird, your bullet doesn't come as close to being sufficient to kill the victim. Hence, you are less of a cause of the death in Bullet-with-Bird than you are in Bullet.

Consider also the following two cases:

Difference: You are the only shooter aiming at a victim. You shoot and the victim dies.

No Difference: Unbeknownst to you, you are one of many shooters who are aiming at a victim. It takes one bullet to kill the victim. You shoot, and so does each of the other shooters. All the bullets reach the victim simultaneously, and the victim dies.

It seems plausible to think that you made a more substantial contribution to the victim's death in Difference than in No Difference. In Difference, the victim's death very crucially depends on you, whereas in No Difference the victim would have died even if you weren't there. We can account for this thought via the following criterion:

(Necessity Criterion) How much a cause contributes to an effect is a matter of how close it comes to providing a necessary condition for an effect.

In Difference, your bullet is necessary to kill the victim - whether the victim lives or dies hinges on what you do. Whereas in No Difference, your bullet is one among many that are sufficient to kill the victim — it's far from being necessary for the victim's death. Hence, you are more of a cause of the victim's death in Difference than in No Difference.

The trouble begins, Sartorio argues, once we contrast Bullet-with-Bird with No Difference. Notice that your bullet is sufficient to kill the victim in No Difference, but not in Bullet-with-Bird. Notice also that your bullet is necessary for the victim's death in Bullet-with-Bird, but not in No Difference. It follows that according to Sufficiency Criterion you're more of a cause of the victim's death in No Difference, but according to Necessity Criterion this is false. And according to Necessity Criterion you're more of a cause of the victim's death in Bullet-with-Bird, but according to Sufficiency 
Criterion this is false. Pointing out this mismatch, Sartorio raises the question as to in which case you actually are more of a cause. In response, she says:

Here I am at a loss about what to say. I feel like I just do not have any clear intuitions anymore. I find myself wanting to say: well, in a sense, [the] contribution is more significant in [one] case, and in another sense it is more significant in the [other] case. But this is unhelpful. (Sartorio 2020, p. 352)

She concludes that the idea that causation comes in degrees is an illusion. ${ }^{18}$

However, this conclusion is unwarranted. It seems premature. We don't typically think that if two accounts of $x$ sometimes give us conflicting results about $x$, (it's good reason to think that) $x$ is an illusion. Take, for instance, two principles of morally right action - the utilitarian principle and the Categorical Imperative. Sometimes they give us conflicting results about whether an action is morally right. But hardly anyone concludes because of this that moral rightness is an illusion.

Indeed, more similarly to the subject at hand, theories of causation sometimes conflict in their verdicts about whether a given factor is a cause of an outcome or not. Take a simple counterfactual theory of causation according to which, again, $c$ is cause of $e$ just in case had $c$ not occurred $e$ would not have occurred. This theory can't properly account for overdetermination, since in overdetermination there are multiple sufficient causes. ${ }^{19}$ Take any of the factors involved in an overdetermination case, it's false that had that factor not occurred the outcome wouldn't have occurred. Hence, we get the result that for any given factor involved in overdetermination, that factor isn't a cause of the outcome. But, according to one prominent productive theory of causation, causation is a matter of energy transference between a cause and an effect. Hence, if there's energy transference between a factor and the outcome in an overdetermination case, that factor counts as a cause of the outcome. Plausibly then each of those factors involved in that overdetermination case counts as a cause of the outcome (Moore 2009, p. 105). For another well-known example, while productive theories typically can't count omissions as causes, counterfactual theories typically can (Paul and Hall 2013, pp. 190-5). Consequently, some think that this counts against productive theories of causation while some think that omissions can't be causes. We can further multiply these sorts of examples. The point is that no one concludes based on these considerations that causation is an illusion.

To be fair, Sartorio's argument also includes explaining away "the appearances" in some cases where we need degrees of causation. Hence, as Sartorio (in personal com-

\footnotetext{
${ }^{18}$ Sufficiency Criterion and Necessity Criterion might turn out to be a single criterion which might eliminate the mismatch in question. There's also some empirical support for the idea that the best way to account for the seemingly competing causal judgements based on necessity and sufficiency is via a unified account of degrees of causation (Icard, Kominsky, and Knobe 2017). However, this may not be enough to respond to Sartorio. As she grants it, there are still other plausible criteria for measuring degrees of causation, and she would contend that she could come up with other examples of the same kind of mismatch using them instead (cf. Sartorio 2020, p. 351).

${ }^{19}$ Cf. Moore (2009, p. 354) and Dowe (2013, pp. 115-6) for brief discussions on this. For ease of exposition, I use the simple counterfactual theory of causation. But even the more sophisticated counterfactual theories of causation can't properly account for overdetermination (Paul and Hall 2013, pp. 149-51).
} 
munication) draws my attention to it, her argument is of the following kind: Here's a puzzle about $x$, and the best way out of it is explaining away the appearances about $x$. However, this still seems problematic to me for three reasons. First, as I'll show in section six below, the kind of cases where we need degrees of causation span much wider. Second, it seems premature to call for explaining away the appearances based on the given reason. It's ubiquitous in philosophy that competing theories on a given subject sometimes give us conflicting results. Compatibilist and libertarian theories sometimes give us conflicting results about whether someone is morally responsible. Internalist and externalist theories of epistemic justification sometimes give us conflicting results about whether a given belief is justified. The utilitarian principle and the Categorical Imperative sometimes conflict in their verdicts about whether a given action is morally right. But hardly anyone calls for explaining away moral responsibility, or epistemic justification, or moral rightness because of this. Third, the call for explaining away the appearances seems premature also because degrees of causation hasn't received much attention in the causation literature yet (Tadros 2018, p. 408). Due partly to this lack of attention, Mumford says that he would hope that all future theories of causation take as a desideratum that degrees of causation must be accommodated (Mumford 2013, p. 111, my emphasis). I conclude then that the third objection doesn't show that causation doesn't come in degrees.

\section{Objection 4: unacceptable moral implications}

We now turn to the fourth and final objection. It is sometimes argued that the thesis that causation comes in degrees leads to unacceptable moral results. ${ }^{20}$ Consider the case of ten teenagers again. Suppose they're trying to push the boulder down the hill to save a climber's life who got stuck under that boulder. They are of varying strengths - say, one is a little bit stronger than all the others who are equally strong. But all of them do everything they can to save the climber. And again, none of them are strong enough to push the boulder on their own, and hence each of them is needed for the outcome. They push the boulder down the hill and save the climber.

If causation comes in degrees, it seems plausible to think that the strongest teenager is more of a cause of saving the climber's life than all the others. This might in turn imply that she is more morally responsible-i.e., more praiseworthy-than all the others. However, one might object that this is implausible. It's not like any of the rest of the teenagers worked any less. They held nothing back. Each of them did everything they can to save the climber. Hence, the objector continues, all the teenagers deserve equal degree of moral praise. The objector then concludes as follows. Since the false result that the strongest teenager deserves more moral praise follows from the thesis that causation comes in degrees, this thesis must be false.

In response, firstly, even if the result in question is implausible, it doesn't follow that causation doesn't come in degrees. The argument above is this:

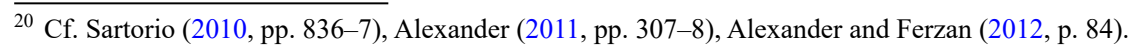


$\mathbf{P 1}$. If causation comes in degrees, then the strongest teenager is more morally praiseworthy than all others.

P2. The strongest teenager is not more morally praiseworthy than all others.

C. Hence, causation doesn't come in degrees.

However, one might question whether the consequent of P1 is entailed by the thesis that causation comes in degrees. After all, what follows from this thesis alone is at most that the strongest teenager is more of a cause of saving the climber than all others. That the strongest teenager is more morally praiseworthy follows only when we pair this thesis with an additional thesis: all else equal, the more one causally contributes to an outcome, the more morally praiseworthy one is for that outcome. That is, roughly, moral responsibility in the basic desert sense is proportionate to causal contribution. ${ }^{21}$ Call this thesis Proportionality. So now P1 above must be revised as follows:

P1*. If causation comes in degrees and moral responsibility is proportionate to causal contribution, then the strongest teenager is more morally praiseworthy than all others.

The new conclusion of the above argument will then be as follows:

$\mathrm{C}^{*}$. It is false that: causation comes in degrees and moral responsibility is proportionate to causal contribution.

Equivalently, $\mathbf{C} *$ says that either causation doesn't come in degrees or moral responsibility is not proportionate to causal contribution. But this is far from showing that causation doesn't come in degrees. It's consistent to hold that causation comes in degrees, but that Proportionality is false. ${ }^{22}$

Secondly, notice that even the claim that the strongest teenager causally contributes more to saving the climber than all others isn't entailed by the thesis that causation comes in degrees. This is because the claim assumes a specific criterion for measuring degrees of causation-i.e., something like the productive account of causal contribution mentioned above. There might be other criteria for measuring degrees of causation that tells us that all the teenagers causally contributed equally to saving the climber. In that case, one could reject $\mathbf{P 1}$ * and avoid $\mathbf{C} *$. Hence, one might embrace both Proportionality and the thesis that causation comes in degrees. Indeed, it might turn out that all or most of the plausible criteria for measuring degrees of causation, when paired with Proportionality, entail implausible results. In that case, one could still revert to holding that causation comes in degrees and denying Proportionality.

\footnotetext{
${ }^{21}$ Some philosophers hold that this is true (e.g., Mumford 2013, Bernstein 2016, 2017). After Bernstein (2017), I'll call this thesis Proportionality.

22 Some philosophers hold that moral responsibility (i.e., blameworthiness and praiseworthiness) depends only factors internal to agents (Kershnar 2018, ch.7, Khoury 2018). If this is true, then causal contribution is irrelevant to moral responsibility, and hence it's false that moral responsibility is proportionate to causal contribution.
} 
Third, and lastly, one might want to resist the idea that the result in question is implausible. After all, many philosophers believe that what one causes is relevant to - i.e., increases - one's degree of moral responsibility in the basic desert sense. ${ }^{23}$ If this is correct, then it's plausible to hold that one's degree of moral responsibility for an outcome should increase proportionately with the degree to which one causes that outcome. That is, one should be morally responsible only for the part or the proportion of the outcome that one causes. One might then hold that the strongest teenager is more praiseworthy than the others because she did more of the saving. I conclude then that the fourth objection doesn't show that causation doesn't come in degrees.

\section{It is too costly to deny that causation comes in degrees}

I presented the four main objections from the literature to the thesis that causation comes in degrees and argued that they fail. Now why should we think that this thesis is true? Relatedly, what is the cost of denying this thesis?

Let's begin by noting that our everyday thought and talk make extensive use of a graded notion of causation. We often wonder about degrees of 'causal potency,' of 'causal contribution,' of 'causal efficacy'; something being a 'main,' 'chief,' or 'principal' cause of an outcome; something being 'stronger/weaker,' 'more/less important,' cause of an outcome. For instance, one might wonder if it's the bad road conditions or poor driving skills that's more of a cause of traffic accidents. One might wonder whether it's the traffic or his driving skills that contributes more to his being often late to work. A high school student might believe that it's more because of her math teacher than any other of her teachers that she's graduating with honors. A young novelist might hold that Emily Brontë is the most important reason why he's a novelist. $^{24}$

Note that these sorts of inquiries and beliefs also affect our attitudes and behaviors in very specific ways. Plausibly, if it's the bad road conditions that's more of a cause of accidents, we would prioritize investing into fixing the roads. If it's more or mainly due to your poor driving skills that you're often late to work, you might want to invest into improving your driving skills. If it it's more or mainly due to traffic that you're often late, you might want to consider relocating instead. The high school student above presumably will respect her math teacher more than any other of her teachers, and might even plan on keeping in touch with the math teacher after graduation. The

\footnotetext{
${ }^{23}$ Cf. e.g., Moore (2011, p. 496), Rosen (2011, p. 405), Mumford (2013, pp. 109-10). While Moore (2011, p. 496) says "roughly one-half of the philosophic community" accepts it, Mumford (2013, p. 109) even says that the idea is "perhaps... too self-evident to require an argument at all." Also, basically all those who accept resultant moral luck are committed to the idea that one's causal responsibility increases one's moral responsibility in the basic desert sense. Cf. Nelkin (2019) for a recent overview on the debate over moral luck.

${ }^{24}$ Ordinary expressions of causal judgements - especially taken on their own — might be approached with caution for they might be indicative of that which is little metaphysical significance. However, it should be a virtue of a view if it's consistent with such expressions. Also, a growing body of psychology literature presents considerable empirical evidence that people's causal judgements themselves presuppose a graded notion of causation (cf., e.g., Lagnado et al., 2014, Gerstenberg et al., 2018, Langenhoff et al., forthcoming).
} 
young novelist above might be willing to buy a well-preserved, first edition copy of Emily Brontë's classic novel Wuthering Heights even if the price is exorbitant. Note that these thoughts and attitudes seem intuitively very plausible. Note also that it's hard to see how we could properly make sense of these thoughts and attitudes if we deny that causation admits of degrees.

A graded notion of causation also undergirds many substantial scientific, legal, and philosophical theses. For instance, a historian might think that nationalism was more of a cause of the First World War than militarism. A physicist might think that gravity is more of a cause of a particle's acceleration than the presence of an electric field. A medical scientist or a physician might think that one medicine is more causally effective in curing a certain illness than another, or wonder how causally powerful a certain carcinogen is to kill patients. ${ }^{25}$ Consider also the very live debate, among experts from various scientific fields, on what factor (e.g., which country, politician, or policy) is more of a cause of the Covid-19 pandemic death toll. These sorts of theses and inquiries seem perfectly sensible, and again they have wide ranging affects - from our personal attitude towards a politician to a country's position in international relations.

Moreover, how significant a causal role one plays in generating an outcome can be relevant to the degree of one's moral duty in reparations, or one's legal liability, regarding that outcome (Miller 2001, Moore 2009, Kaiserman 2017). Whether it was the rain or a driver's degree of drunkenness that was the main cause of an accident can be relevant in personal or legal disputes. Of the two relevant factories, how much each of them contributed to the pollution of a river can be relevant for the question regarding reparations. It's again difficult to see how we can properly make sense of any of these thoughts and theses if we deny that causation comes in degrees. It seems then that a graded notion of causation is intuitively very plausible, and its denial is theoretically too costly.

Now, I don't deny that there might be competing explanations - ones that don't appeal to degrees of causation - for (at least some of) the thoughts, theses, and attitudes above. One might wonder, for instance, whether what undergirds the scientific theses above is a notion of degrees of explanatory importance rather than degrees of causation. ${ }^{26}$ Recall also the discussion in the previous section that one's degree of moral responsibility (i.e., blameworthiness and praiseworthiness) might have nothing to do with degrees of causation. So, one might wonder whether degrees of moral responsibility can be accounted for solely in terms of other potentially relevant factors like one's intentions, or epistemic status. However, firstly, considering the long list of a wide range of thoughts, theses, and attitudes above, it would be highly surprising if it turned out that all the items in the list are accounted for without appealing to degrees of causation. Secondly, even if there are such competing explanations for

\footnotetext{
${ }^{25}$ Cf. Northcott (2005a, 2005b, 2013), Korb, Nyberg, and Hope (2011), Kaiserman (2016, 2018), Sprenger (2018) for further examples and more detailed discussion.

${ }^{26}$ Thanks to an anonymous referee for suggesting this potential explanation. (However, cf. e.g., Sprenger (2018) who observes a distinction between degrees of explanation and degrees of causation, and still contends that a graded notion of causation undergirds many scientific theses.) Thanks also to Carolina Sartorio for raising the concern that there might be other explanations for the thoughts, theses, and attitudes mentioned above.
} 
all of them, considerations from theoretically unity would speak in favor of degrees of causation. This is because while the degrees of causation explanation provides a single principle to account for all of them, it's more likely than not that these competing explanations would be different in kind and not grounded in a single principleconsidering, again, the range of items in the list. And thirdly, given that a graded notion of causation is intuitively plausible and all the main objections against it fail, the burden of proof - to show that the items in the list don't presuppose graded causation-is on those who deny it.

\section{Conclusion}

I argued that the four main objections in the literature against the thesis that causation comes in degrees fail. I also showed that this thesis undergirds a wide-ranging portion of our everyday thought and talk, our small- or large-scale attitudes, and a variety of substantial scientific, legal, and philosophical theses. In short, we don't have good reasons to reject this thesis, and it's too costly to deny it. Hence, I conclude that causation comes in degrees.

Indeed, one might still wonder why some authors would oppose this thesis if its implicit or explicit use is so widespread as I suggest it. I suspect it's largely because this thesis hasn't received much attention in the causation literature yet. I think another reason why some might be suspicious about this thesis is that - as the foregoing discussions suggests - it's not always clear what's meant by degrees of causation to begin with. I hope that my paper also raises an awareness about this problem in the literature and remedies it to an extent.

Acknowledgements I am greatly indebted to Sara Bernstein, Ben Bradley, Andrei Buckareff, Mark Heller, Hille Paakkunainen, and Carolina Sartorio for their invaluable feedback on various versions of this paper. I would like to also thank two anonymous referees for their excellent comments that helped me improve the paper. Many thanks to Ben Cook, Neil Feit, Vera Hoffmann-Kolss, Stephen Kershnar, Max Kistler, Sanggu Lee, and Matthias Rolffs for helpful discussions on ideas presented in this paper. Many thanks also to the audience at, and organizers of, 20th Annual Pitt-CMU Graduate Student Philosophy Conference, AGENT, Ethics and Normativity Talks (2019) in University of Texas at Austin, ABD Workshop Series 2020 in Syracuse University, Department of Philosophy, 94th Joint Session of the Aristotelian Society and the Mind Association, and Sixth Annual Conference of the Society for the Metaphysics of Science where I have presented various versions of this paper or arguments that ended up in this paper.

Funding (Not Applicable)

Availability of data and material (Not Applicable)

Code availability (Not Applicable)

\section{Declarations}

Conflicts of interest/competing interests I declare that there is no conflict of interest. 


\section{References}

Alexander, L. (2011). Michael Moore and the mysteries of causation in the law. Rutgers Law Journal, 42, 301-314

Alexander, L., \& Ferzan, K. K. (2012). "More of Less" Causation and Responsibility. Criminal Law and Philosophy, 6, 81-92

Barker, K., \& Steele, J. (2015). Drifting Towards Proportionate Liability: Ethics and Pragmatics. Cambridge Law Journal, 74, 1:49-77

Bebe, H. (2013). Legal Responsibility and Scalar Causation. Jurisprudence, 4(1), 102-108

Bernstein, S. (2016). Causal and Moral Indeterminacy. Ratio, 29(4), 434-447

Bernstein, S. (2017). Causal Proportions and Moral Responsibility. In D. Shoemaker (Ed.), Oxford Studies in Agency and Responsibility (pp. 165-182). Oxford: Oxford University Press

Braham, M., \& van Hees, M. (2009). Degree of Causation. Erkenntnis, 71(3), 323-344

Chockler, H., \& Halpern, J. Y. (2004). Responsibility and Blame: A Structural-Model Approach. Journal of Artificial Intelligence Research, 22, 93-115

Dowe, P. (2000). Physical Causation. Cambridge: Cambridge University Press

Dowe, P. (2013). Moore's Account of Causation and Responsibility, and the Problem of Omissive Overdetermination. Jurisprudence, 4(1), 115-120

Eells, E. (1991). Probabilistic Causality. Cambridge: Cambridge UP

Feldman, R. (2003). Epistemology. Upper Saddle River, NJ: Prentice Hall

Fitelson, B., \& Hitchock, C. (2011). Probabilistic Measures of Causal Strength. Causality in the Sciences, Illari, P. M., Russo, F., Williamson J. (eds.), (pp. 600-27), New York, OUP

Gerstenberg, T., Ullman, T. D., Nagel, Jonas, K. W., Max, Lagnado, D. A., \& Tenenbaum, J. B. (2018). Lucky or clever? From Expectations to Responsibility Judgments. Cognition, 177, 122-141

Gerstenberg, T., Goodman, N. D., Lagnado, D. A., \& Tenenbaum, J. B. (forthcoming). A Counterfactual Simulation Model of Causal Judgments for Physical Events. Psychological Review

Hall, N. (2000). Causation and the Price of Transitivity. Journal of Philosophy, 97, 198-222

Hall, N. (2004). In J. Collins, N. Hall, \& L. A. Paul (Eds.), Two Concepts of Causation. Causation and Counterfactuals (pp. 225-276). Cambridge, MA: MIT Press

Icard, T. F., Kominsky, J. F., \& Knobe, J. (2017). Normality and Actual Causal Strength. Cognition, 161, 80-93

Kaiserman, A. (2016). Causal Contribution. Proceedings of the Aristotelean Society, 116:387-394

Kaiserman, A. (2017). Partial Liability. Legal Theory, 23, 1-26

Kaiserman, A. (2018). 'More of a Cause': Recent Work on Degrees of Causation and Responsibility. Philosophy Compass, 13(7), e12498

Kershnar, S. (2018). Total Collapse: The Case Against Responsibility and Morality. Cham, Switzerland: Springer

Khoury, A. (2018). The Objects of Moral Responsibility. Philosophical Studies, 175, 1357-1381

Korb, K. B., Nyberg, E., \& Hope, L. (2011). A New Causal Power Theory. Causality in the Sciences, Illari, P. M., Russo, F., Williamson J. (eds.), (pp. 628-652), New York, OUP

Langenhoff, A. F., Wiegmann, Alex, Halpern, J. Y., Tenenbaum, J. B., \& Gerstenberg, Tobias. (forthcoming) Predicting Responsibility Judgments from Dispositional Inferences and Causal Attributions. Cognitive Psychology

Lagnado, D., A., Gerstenberg, Tobias, and Zultan, Ro'i. (2014). Causal Responsibility and Counterfactuals. Cognitive Science, 37:1036-1073

Lewis, D. (2004). In J. Collins, N. Hall, \& L. A. Paul (Eds.), Causation as Influence. Causation and Counterfactuals (pp. 75-106). Cambridge, MA: MIT Press

Miller, D. (2001). Distributing Responsibilities. The Journal of Political Philosophy, 9(4), 453-471

Moore, M. S. (2009). Causation and Responsibility: An Essay in Law, Morals, and Metaphysics. Oxford: Oxford University Press

Moore, M. S. (2011). Causation Revisited. Rutgers Law Journal, 42, 451-509

Moore, M. S. (2012). Moore's Truths About Causation and Responsibility: A Reply to Alexander and Ferzan. Criminal Law and Philosophy, 6, 445-462

Moore, M. S. (2013). Author's Reply. Jurisprudence, 4(1), 121-137

Mumford, S. (2013). Causes for Laws. Jurisprudence, 4(1):109-14

Nelkin, D. K. (2019). Moral Luck. The Stanford Encyclopedia of Philosophy (Summer 2019 Edition), Edward N. Zalta (ed.), https://plato.stanford.edu/archives/sum2019/entries/moral-luck/ 
Northcott, R. (2005a). Comparing Apples with Oranges. Analysis, 65(1), 12-18

Northcott, R. (2005b). Pearson's Wrong Turning: Against Statistical Measures of Causal Efficacy. Philosophy of Science, 72(5), 900-912

Northcott, R. (2008). Weighted Explanations in History. Philosophy of the Social Sciences, 38(1), 76-96

Northcott, R. (2013). Degree of Explanation. Synthese, 190(15), 3087-3105

Paul, L. A., \& Hall, E. J. (2013). Causation: A User's Guide. Oxford: Oxford University Press

Pappas, G. (2017). Internalist vs. Externalist Conceptions of Epistemic Justification. The Stanford Encyclopedia of Philosophy, Edward N. Zalta (ed.), https:/plato.stanford.edu/archives/fall2017/entries/ justep-intext/

Pearson, R. N. (1980). Apportionment of Losses Under Comparative Fault Laws-An Analysis of the Alternatives. Louisiana Law Review, 40(2), 323-372

Rosen, G. (2011). Causation, Counterfactual Dependence and Culpability: Moral Philosophy in Michael Moore's Causation and Responsibility. Rutgers Law Journal, 42, 405-434

Sartorio, C. (2010). Causation and Responsibility by Michael S. Moore. Mind, 119, 830-838

Sartorio, C. (2015). A New Form of Moral Luck?. In A. Buckareff, C. Moya, \& S. Rosell (Eds.), Agency, Freedom, And Moral Responsibility (pp. 134-149). New York: Palgrave-Macmillan

Sartorio, C. (2020). More of a Cause? Journal of Applied Philosophy, 37(3), 346-363

Schaffer, J. (2016). The Metaphysics of Causation. The Stanford Encyclopedia of Philosophy, Edward N. Zalta (ed.), https://plato.stanford.edu/archives/fall2016/entries/causation-metaphysics/

Sprenger, J. (2018). Foundations of Probabilistic Theory of Causal Strength. Philosophical Review, 127(3), 371-398

Tadros, V. (2018). Causal Contributions and Liability. Ethics, 128, 402-431

Zimmerman, M. J. (1985). Sharing Responsibility. American Philosophical Quarterly, 22, 115-122

Publisher's note Springer Nature remains neutral with regard to jurisdictional claims in published maps and institutional affiliations. 